\title{
A Three-Dimensional Carbon Nano-Network for High Performance \\ Lithium Ion Batteries
}

Miao Tian ${ }^{1}$, Wei Wang ${ }^{2}$, Yang Liu ${ }^{3}$, Katherine L. Jungjohann ${ }^{3}$, C. Thomas Harris ${ }^{3}$, Yung-

Cheng Lee ${ }^{1}$, and Ronggui Yang ${ }^{1} *$

${ }^{1}$ Department of Mechanical Engineering, University of Colorado, Boulder, CO 80309 (USA)

${ }^{2}$ Advanced Li-ion Batteries Engineering Lab, Ningbo Institute of Material Technology and Engineering, Chinese Adademy of Sciences, Ningbo, 315201 Zhejiang (P. R. China)

${ }^{3}$ Center for Integrated Nanotechnologies (CINT), Sandia National Laboratories, Albuquerque, NM 87123 (USA)

*Corresponding author. Tel.: +1-303-735-1003; fax: +1-303-492-3498.

E-mail address: ronggui.yang@colorado.edu (R. G. Yang) 
Abstract: Three-dimensional (3D) network structure has been envisioned as a superior architecture for lithium ion battery (LIB) electrodes, which enhances both ion and electron transport to significantly improve battery performance. Herein, a 3D carbon nano-network is fabricated through chemical vapor deposition of carbon on a scalably manufactured 3D porous anodic alumina (PAA) template. As a demonstration on the applicability of 3D carbon nano-network for LIB electrodes, the low conductivity active material, $\mathrm{TiO}_{2}$, is then uniformly coated on the 3D carbon nano-network using atomic layer deposition. High power performance is demonstrated in the $3 \mathrm{D} \mathrm{C} / \mathrm{TiO}_{2}$ electrodes, where the parallel tubes and gaps in the 3D carbon nano-network faciliates fast $\mathrm{Li}$ ion transport. A large areal capacity of $\sim 0.37$ $\mathrm{mAh} \cdot \mathrm{cm}^{-2}$ is achieved due to the large $\mathrm{TiO}_{2}$ mass loading in the $60 \mu \mathrm{m}$-thick $3 \mathrm{D} \mathrm{C} / \mathrm{TiO}_{2}$ electrodes. At a test rate of $\mathrm{C} / 5$, the $3 \mathrm{D} \mathrm{C} / \mathrm{TiO}_{2}$ electrode with $18 \mathrm{~nm}$-thick $\mathrm{TiO}_{2}$ delivers a high gravimetric capacity of $\sim 240 \mathrm{mAh} \cdot \mathrm{g}^{-1}$, calculated with the mass of the whole electrode. A long cycle life of over 1000 cycles with a capacity retention of $91 \%$ is demonstrated at $1 \mathrm{C}$. The effects of the electrical conductivity of carbon nano-network, ion diffusion, and the electrolyte permeability on the rate performance of these $3 \mathrm{D} \mathrm{C} / \mathrm{TiO}_{2}$ electrodes are systematically studied.

Keywords: Three-dimensional nano-network, carbon, Li-ion battery, anode

\section{Introduction}

The rapid development of portable electronics and electric vehicles has led to a great demand for high energy density, high power, and long cycle-life lithium-ion batteries (LIBs). Since energy is released or stored in LIBs by the flow of $\mathrm{Li}$ ions and electrons between the anode and cathode electrodes [1-3], the efficient transport of Li ions and electrons is the key to the energy and power density of LIBs. Three-dimensional (3D) micro/nanostructured networks present great benefits for high performance LIBs, such as a large surface area for 
fast $\mathrm{Li}$ ion insertion/extraction, interconnecting paths for fast electron conduction, and high porosity for fast electrolyte diffusion and volume change alleviation [4-6]. An ultra-high rate of over 1000C LIB was demonstrated using porous Ni framework with pore size of $\sim 2 \mu \mathrm{m}$ as conductive network loaded with lithiated $\mathrm{MnO}_{2}$ [7]. Similarly high areal capacity and excellent rate performance have been achieved in batteries with active materials such as $\mathrm{LiCoO}_{2}$ [8], $\mathrm{Fe}_{3} \mathrm{O}_{4}[9], \mathrm{TiO}_{2}[10]$, and silicon [11] on 3D metal networks. However, metallic conducting networks are usually too heavy as inactive materials, which significantly reduce the gravimetric capacity of these 3D LIB electrodes. On the other hand, low mass density conducting carbon nanostructures, such as carbon nanotubes, activated carbon fiber papers, and graphene has been widely explored to overcome the density barrier [12-14]. Electrodes consists of random mixture of active materials and conducting carbon nanostructures, such as carbon fiber papers and graphene papers, usually suffers from non-uniform distribution of active material or conductive medium $[15,16]$, which does not form a contituous conducting network or a uniform electrolyte diffusion channel. One-dimensional carbon nanotube or nanofiber array might offer straight channels for fast electrolyte diffusion into the electrodes. However, the thickness and the performance of such electrodes are usually limited by the agglomeration of nanotubes/nanofibers $[17,18]$. Porous carbon structure with well-controlled and uniform pore size is thus desirable for stable and high performance electrodes. Carbon aerogels consisted of meso-pores with a size of $<10 \mathrm{~nm}$ offer very high surface areas for LIB and supercapacitors [19-21]. However, the diffusion of the electrolyte and transport of ions are greatly impeded due to the small pores in carbon aerogels, especially when the electrodes are thicker than $10 \mu \mathrm{m}$ [22], which greatly harms the rate capability of the electrodes [23-25]. For example, mesoporous carbon/ $/ \mathrm{Co}_{3} \mathrm{O}_{4}$ composite maintained only $32 \%$ of its capacity when the test current was increased by 10 times from $200 \mathrm{~mA} \cdot \mathrm{g}^{-1}$ to $2000 \mathrm{~mA} \cdot \mathrm{g}^{-1}$ [25]. As such, porous carbon with large pore sizes $(>1 \mu \mathrm{m})$ was developed to improve the rate capability of electrodes [26, 27]. A $\mathrm{LiFePO}_{4} /$ carbon composite electrode with $1 \mu \mathrm{m}$ to $5 \mu \mathrm{m}$ pores retained 
$89 \%$ of its capacity when the test rate was increased by 10 times from $\mathrm{C} / 10$ to $1 \mathrm{C}[28,29]$. Accompanying with the improved power performance of these electrodes, the volumetric capacity and energy density are greatly reduced due to the large size of the pores and the thin active materials, which leaves most space in the porous electrodes empty.

A low mass-density conducting network with pore size in the range of hundreds of nanometers is in great need, which could potentially enhance both ion and electron transport without sacrificing energy density. Some efforts have been made to develop 3D conducting networks with pore size in the range of several hundred nanometers. Porous carbon with pore size of $~ 300 \mathrm{~nm}$ encapsulated with sulfur retained $52 \%$ of its capacity when test rate was increased by 10 times from $\mathrm{C} / 5$ to $2 \mathrm{C}$ [30]. Nanoparticles entrapped in carbon inverse opal with $220 \mathrm{~nm}$ diameter pores maintained $50 \%$ of the capacity when the test current increased 10 times from $1 \mathrm{~A}^{\prime} \mathrm{g}^{-1}$ to $10 \mathrm{~A} \cdot \mathrm{g}^{-1}$ [31]. All these previous efforts demonstrate the importance of the 3D conducting network with appropriate pore size in the LIB electrodes.

In this work, we develop a novel 3D carbon nano-network as highly efficient current collector for the high-power and long-cycle-life LIB electrodes. The 3D carbon nano-network, synthesized by chemical vapor deposition (CVD) of carbon on 3D porous anodic alumina (PAA) templates [32], consists of parallel trunk carbon tubes connected together by numerous branch carbon tubes to form an interconnected network (See Section 1 of the Supporting information for the 3D configuration and fabrication process). The diameters of both the trunk tubes and the branch tubes are in the range of hundreds of nanometers, which are ideal as 3D porous current collector for the LIB electrodes as articulated earlier. The thickness of these carbon tube walls is controllable from a few nanometers to tens of nanometers depending on the carbon CVD time. As a demonstration, the low conductivity active material, $\mathrm{TiO}_{2}$, is then uniformly coated on the 3D carbon nano-network using the atomic layer deposition (ALD) process. Electrochemical performance of such $3 \mathrm{D} \mathrm{C} / \mathrm{TiO}_{2}$ nano-network electrodes were 
tested, which demonstrates large areal capacity, high gravimetric capacity, long cycle life and high rate capability. The effects of the electrical conductivity of carbon nano-network, ion diffusion in the active material, and the electrolyte permeability on the rate performance of these $3 \mathrm{D} \mathrm{C} / \mathrm{TiO}_{2}$ electrodes are systematically studied, which gives insights on high performance LIB electrodes with 3D architecture.

\section{Experimental Section}

\subsection{Sample Preparation}

A 3D carbon nano-network was fabricated by chemical vapor deposition (CVD) of carbon on the 3D porous anodic alumina (PAA) templates. The fabrication of 3D PAA templates using low purity 1000 series (99\% purity, McMaster 9060K16) Al foils was described in an earlier paper [33]. The 3D PAA template was first sputtered with a $100 \mathrm{~nm}$ thick $\mathrm{Au}$ layer for electrical conductance and then electrodeposited with Co at $-1.2 \mathrm{~V} v s$. $\mathrm{Ag} / \mathrm{AgCl}$ for $1 \mathrm{~min}$ as the catalyst for the later carbon CVD process [34]. To uniformly deposit carbon on the 3D PAA template, the CVD process takes place at $700{ }^{\circ} \mathrm{C}$ and at the ambient pressure with a gas flow rate of $262 \mathrm{sccm} \mathrm{Ar,} 90 \mathrm{sccm} \mathrm{H}_{2}$, and $60 \mathrm{sccm} \mathrm{C}_{2} \mathrm{H}_{4}$ at $700{ }^{\circ}$ [35]. After CVD, the PAA template was removed by wet etching of $\mathrm{Al}_{2} \mathrm{O}_{3}$ in $1 \mathrm{M} \mathrm{NaOH}$ solution for 5 hours, which leaves the free standing 3D carbon nano-network ready after supercritical drying to be used for the deposition of active materials to form 3D nanostructured electrodes. The thickness of the CVD carbon layer scales linearly with the CVD deposition time (Figure S3a in Section 3 of the Supporting information). $3 \mathrm{~nm}$ thick carbon coating is obtained after 3.5 hours of CVD.

Atomic layer deposition (ALD) is used to uniformly deposit LIB active material, $\mathrm{TiO}_{2}$, on the $3 \mathrm{D}$ carbon nano-network in the kinetic mode with ultra-high purity (UHP) grade $\mathrm{N}_{2}$ as the carrier gas [36]. Base pressure of the reactor was kept below 1 Torr. To facilitate the uniform $\mathrm{ALD} \mathrm{TiO}_{2}$ process, an $\mathrm{Al}_{2} \mathrm{O}_{3}$ (alumina) seed layer of $2 \mathrm{~nm}$ was pre-deposited by 50 cycles of sequential dosing of trimethylaluminum (TMA) for $150 \mathrm{~ms}$ and water for $750 \mathrm{~ms}$ at 
$150{ }^{\circ} \mathrm{C}$ (Section 4 of the Supporting information). An ALD $\mathrm{TiO}_{2}$ layer was then coated with different thickness of $7 \mathrm{~nm}$ to $27 \mathrm{~nm}$ by sequential dosing of $200 \mathrm{~ms}$ Titanium tetrachloride $\left(\mathrm{TiCl}_{4}\right)$ and $750 \mathrm{~ms}$ water at $150{ }^{\circ} \mathrm{C}$ from 150 cycles to 600 cycles.

\subsection{Structural and Electrical Characterization}

The field emission scanning electron microscope (FE-SEM, JEOL JSM-7401F) was used to study the morphology of the 3D carbon nano-networks and the $3 \mathrm{D} \mathrm{C} / \mathrm{TiO}_{2}$ electrodes. Cross-sectional images of the 3D nano-networks were taken by tearing the samples apart with tweezers to expose fresh cross sections and mounting them on a tilted SEM stage. Transmission electron microscopy (TEM, Philips CM-10) and high resolution transmission electron microscopy (HR-TEM, FEI Tecnai F30) were used for structural characterization. Selected area electron diffraction (SAED) pattern was operated under $300 \mathrm{keV}$ electron beam with camera length of $1.2 \mathrm{~m}$. Electrical conductivities of the $3 \mathrm{D}$ nano-networks were tested with the four point probe method (Kulicke \& Soffa model 3007). The electrodes after electrochemical cycling test were carefully taken out of the coin-cell battery in the glovebox and soaked and washed in DMC for 5 times to remove the electrolyte before characterization.

\subsection{Electrochemical Characterizations}

The as-prepared 3D carbon nano-network and 3D C/TiO 2 nanostructured anodes were tested by assembling half-cell in the CR2032 coin-type cell with an electrolyte containing $1 \mathrm{M}$ $\mathrm{LiPF}_{6}$ in ethylene carbonate (EC)/dimethyl carbonate (DMC) (1:1 volume ratio, Aldrich) and with Li foil (Alfa Aesar) as counter-electrode. The CR2032 coin-type cells were assembled in an argon-filled glove box system (Vacuum Atmosphere Nexus model) and tested with a computer controlled potentiostats/galvanostats system (MTI, 5V1mA). The discharge-charge experiments were performed galvanostatically within the voltage window of $1.0-2.6 \mathrm{~V}$ (vs. $\left.\mathrm{Li} / \mathrm{Li}^{+}\right)$.

\section{Results and Discussion}


Figure 1a shows the optical image of a $20 \mathrm{~cm}^{2}$ free-standing 3D carbon nano-network. The sizes of these samples are scalable depending on the size of starting Al foils for PAA template fabrications. The sample has a thickness of $60 \mu \mathrm{m}$, which is determined by the thickness of the 3D PAA template (see Section 5 of the Supporting information for crosssectional images of 3D PAA template and 3D carbon nano-network). Figure 1b shows the cross-sectional scanning electron microscope (SEM) image of a 3D carbon nano-network after 3.5 hour CVD carbon coating. The 3D carbon network consists of parallel trunk tubes (colored to red on left side), which are connected together by branch tubes (colored to green on left side) to form a freestanding film. No agglomeration of the carbon tubes were observed due to the support of the branch tubes between the neighboring carbon tubes, similar to the 3D Ni nanowire network published before [33]. The interconnection of carbon tubes inside the sample was also readily observable by the transmission electron microscope (TEM) characterization, as shown in Figure 1c and 1d. The tube diameter is $\sim 250 \mathrm{~nm}$. Such tube diameter can be tuned at a range of $40-400 \mathrm{~nm}$ by the fabrication process of PAA templates [32]. The thickness of the carbon layers is uniformly $3 \mathrm{~nm}$, after 3.5-hour CVD. The carbon layer thickness is scalable with CVD time (see Section 3 of the Supporting information for the relationship between carbon thickness and CVD time). The high-resolution TEM (HRTEM) image in Figure 1e shows partially crystalline structure of the carbon layer. The selected area electron diffraction (SAED) pattern in the inset figure is consistent with the HRTEM image, showing both amorphous diffraction rings and crystalline diffraction points.

Electrical conductivity of electrodes plays an important role in the rate capabilities of LIBs. A study on phospho-olivines shows that the rate capability was significantly increased (about $57 \%$ capacity retention from $\mathrm{C} / 10$ to $10 \mathrm{C}$ ) when the electrode conductivity increase from $10^{-7} \mathrm{~S} \cdot \mathrm{m}^{-1}$ to $10^{-1} \mathrm{~S} \cdot \mathrm{m}^{-1}$ through doping [37]. As the conducting network for LIB electrodes, the 3D carbon nano-network is expected to have high electrical conductivity so 
that low conductivity active materials can be loaded. The in-plane (vertical to the main carbon tube direction) electrical conductivity of the 3D carbon nano-network film with $3 \mathrm{~nm}$ thick of carbon layer was tested to be $\sim 110 \mathrm{~S} \cdot \mathrm{m}^{-1}$ using the four-probe method (See Section 3 of the Supporting information). By adjusting the thickness of carbon coating via changing the CVD time, the electrical conductivity of the 3D carbon nano-network films can be readily tuned. The thickness of the carbon layer after 10 hours of CVD is increased to $8 \mathrm{~nm}$ and the electrical conductivity is increased to $159 \mathrm{~S} \cdot \mathrm{m}^{-1}$. Usually the ionic conductivity of the electrolyte, (1 M LiPF 6 in ethylene carbonate (EC)/dimethyl carbonate (DMC) (1:1 volume ratio, Aldrich)), which is $\sim 10^{-1} \mathrm{~S} \cdot \mathrm{m}^{-1}$ is the bottleneck of LIB power performance [38, 39]. The electrical conductivity of our as-obtained 3D carbon nano-network is much greater than the ionic conductivity of the electrolytes, which renders great opportunity to enhance the electrical conductivity of low conductivity active materials to meet the requirement of electron transport for high power performance in LIB electrodes [40]. To evaluate the performance of a 3D carbon nano-network as the 3D conductive network in an electrochemical cell, we conducted proof-of-concept studies using $\mathrm{TiO}_{2}$ as the electrochemically active material, since $\mathrm{TiO}_{2}$ has been considered as an attractive material for use in LIB anodes due to its low cost, safety, and environmental benignity [41-43]. The electrical conductivity of amorphous $\mathrm{TiO}_{2}$ is very low, $\sim 10^{-12} \mathrm{~S} \cdot \mathrm{m}^{-1}$, which significantly limits its electrochemical performance [44]. Many efforts have been made to increase the electrical conductivity of $\mathrm{TiO}_{2}$-based anodes by carbon coating, mixing with single-wall carbon nanotubes, mixing with graphene, etc. [45-48]. In this work, by incorporating the 3D conducting carbon nano-network with $\mathrm{TiO}_{2}$, the $3 \mathrm{D} \mathrm{C} / \mathrm{TiO}_{2}$ electrodes have conductivities in the range of 78.1-93.5 S $\cdot \mathrm{m}^{-1}$ (Section 3 of Supporting information).

$\mathrm{TiO}_{2}$ layers with different thicknesses were uniformly deposited on the $3 \mathrm{D}$ carbon nano-networks using the atomic layer deposition (ALD) process [49]. To facilitate the 
uniform $\mathrm{ALD} \mathrm{TiO}_{2}$ process, an $\mathrm{Al}_{2} \mathrm{O}_{3}$ (alumina) seed layer of $2 \mathrm{~nm}$ was pre-deposited (See Section 4 of the Supporting information for the thickness information of the $\mathrm{Al}_{2} \mathrm{O}_{3}$ layers). Earlier research by the authors has shown that this seed layer won't react with Li ions or affect the electrochemical performance of the electrode $[49,50]$. Figure 1f shows a HR-TEM image of the layered structure with the $7 \mathrm{~nm} \mathrm{TiO}{ }_{2}$ coating after 150 cycles of ALD coating. The thickness and the mass loading of $\mathrm{TiO}_{2}$ layer is scalable with ALD cycle number. Three different thicknesses of $\mathrm{TiO}_{2}$ layer were used in this work, $7 \mathrm{~nm}, 18 \mathrm{~nm}$ and $27 \mathrm{~nm}$ with ALD coating cycle numbers of 150, 300 and 600, respectively (See Section 6 of Supporting information for the images and mass loading). The SAED pattern in inset Figure indicates the amorphous nature of $\mathrm{TiO}_{2}$ coating, which is due to low ALD deposition temperature $\left(150^{\circ} \mathrm{C}\right)$ $[51,52]$.

Figure 2a shows that the $60-\mu \mathrm{m}$ thick 3D carbon nano-network film delivers an areal capacity of $\sim 0.03 \mathrm{mAh} \cdot \mathrm{cm}^{-2}$ without any $\mathrm{TiO}_{2}$ coating at $\mathrm{C} / 5$. With the $\mathrm{ALD} \mathrm{TiO}_{2}$ coating, the areal capacities of the electrode were significantly increased to $\sim 0.15 \mathrm{mAh} \cdot \mathrm{cm}^{-2}$ for the 7 nm thick $\mathrm{TiO}_{2}$ sample and to $\sim 0.37 \mathrm{mAh} \cdot \mathrm{cm}^{-2}$ for the $27 \mathrm{~nm}$ thick $\mathrm{TiO}_{2}$ sample at $\mathrm{C} / 5($ Here, $\mathrm{C} / \mathrm{n}$ is referred as the charging/discharging rate to complete one charging/discharging cycle with full capacity $\mathrm{C}$ in $\mathrm{n}$ hours.). With the electrode thickness of $60 \mu \mathrm{m}$, the volumetric capacity is $61.67 \mathrm{mAh} \cdot \mathrm{cm}^{-3}$. High areal capacity and volumetric capacity render high energy density for the whole batteries by reducing the amount of accessary components. In the previous works, an areal capacity of $0.45 \mathrm{mAh} \cdot \mathrm{cm}^{-2}$ was reported for anodized $9 \mu \mathrm{m}$ long $\mathrm{TiO}_{2}$ nanotube arrays at $\mathrm{C} / 10$ [53], and a value of $0.15 \mathrm{mAh} \cdot \mathrm{cm}^{-2}$ for anodized $8.2 \mu \mathrm{m}$ long $\mathrm{TiO}_{2}$ nanotube arrays at $\mathrm{C} / 2$ [54]. Although these nanotube arrays show comparably high areal capacities, their gravimetric capacities and rate capabilities are very poor due to the lack of electrical conducting medium. For example, the gravimetric capacity for the $9 \mu \mathrm{m}$ long $\mathrm{TiO}_{2}$ nanotubes is only $170 \mathrm{mAh} \cdot \mathrm{g}^{-1}$ at $\mathrm{C} / 10$ and $90 \mathrm{mAh} \cdot \mathrm{g}^{-1}$ at $2 \mathrm{C}$ [53]. Some efforts have 
been made to increase the rate capability by incorporating $3 \mathrm{D}$ conducting networks into $\mathrm{TiO}_{2}$ electrodes. A 3D electrode of $\mathrm{TiO}_{2}$ on $\mathrm{Al}$ nanorods reaches $0.01 \mathrm{mAh} \cdot \mathrm{cm}^{-2}$ at $\mathrm{C} / 5$ [10] and a $32 \mu \mathrm{m}$ thick 3D Ni nanowire network coated with $\mathrm{ALD} \mathrm{TiO}_{2}$ delivered an areal capacity of $0.13 \mathrm{mAh} \cdot \mathrm{cm}^{-2}$ at $\mathrm{C} / 4$ [33]. Due to the high weight percentage of the metal conducting networks, the gravimetric capacity of such 3D electrodes with metallic conducting networks cannot keep up with the high areal capacities. In comparison, our novel lightweight 3D carbon nano-network can potentially realize high areal capacity, high gravimetric capacity, and high rate capability simultaneously.

There are different ways to calculate the gravimetric capacities of electrodes depending on whether the mass of only the active material or the whole electrode is used. Figure $2 \mathbf{b}$ shows that the gravimetric capacities of $7 \mathrm{~nm}$ and $18 \mathrm{~nm}$ thick $\mathrm{TiO}_{2}$ coatings have a similar value of $\sim 260 \mathrm{mAh} \cdot \mathrm{g}^{-1}$ at $\mathrm{C} / 5$ when calculated by subtracting the areal capacity of the 3D carbon nano-network from that of the tested electrodes and divided by the mass loading of $\mathrm{TiO}_{2}$. This value is higher than earlier works on pure $\mathrm{TiO}_{2}$ nanotubes $(223$ $\mathrm{mAh} \cdot \mathrm{g}^{-1}$ at 1C) [55], and comparable to porous $\mathrm{TiO}_{2}$ nanowire arrays $\left(265 \mathrm{mAh} \cdot \mathrm{g}^{-1}\right.$ at $\left.\mathrm{C} / 5\right)$, likely benefitting from the conducting network [56]. However, the reversible gravimetric capacity becomes smaller, $\sim 195 \mathrm{mAh} \cdot \mathrm{g}^{-1}$ when the $\mathrm{TiO}_{2}$ layer thickness increases to $27 \mathrm{~nm}$ in $3 \mathrm{D} \mathrm{C} / \mathrm{TiO}_{2}$.

When the contribution of the 3D carbon network to the capacity and mass are both counted in, Figure $2 \mathrm{~b}$ shows whole electrode gravimetric capacities of $\sim 228 \mathrm{mAh} \cdot \mathrm{g}^{-1}$ for the $7 \mathrm{~nm} \mathrm{TiO}{ }_{2}$ electrode and $\sim 235 \mathrm{mAh} \cdot \mathrm{g}^{-1}$ for the $18 \mathrm{~nm} \mathrm{TiO}{ }_{2}$ electrode. By using light-weight carbon instead of a metallic conducting network, the gravimetric capacity of the whole electrode is increased dramatically compared to earlier works on nanostructured $\mathrm{TiO}_{2}$ electrodes. In an earlier work using $\mathrm{Ni}$ as conducting network with similar fabrication and testing process, the overall gravimetric energy density of the electrodes was only $\sim 37 \mathrm{mAh} \cdot \mathrm{g}^{-}$ 
${ }^{1}$ where inactive Ni counts $\sim 81$ wt $\%$ while the active material $\mathrm{TiO}_{2}$ counts only $\sim 15 \mathrm{wt} \%$ [33]. The gravimetric capacities based on whole electrodes are only $87-175 \mathrm{mAh} \cdot \mathrm{g}^{-1}$ in other nanostructured $\mathrm{TiO}_{2}$ electrodes such as nanocrystallites, nanoparticle, nanowires, and nanotubes with $50 \%$ - $70 \%$ weight percentage of $\mathrm{TiO}_{2}$ where carbon black and polymer binders are often added [57-62].

Figure 2c shows the galvanostatic discharging/charging curves of the $3 \mathrm{D} \mathrm{C} / \mathrm{TiO}_{2}$ electrodes with $3 \mathrm{~nm}$ thick carbon and $7 \mathrm{~nm}$ thick $\mathrm{TiO}_{2}$ tested at $\mathrm{C} / 5$. Due to the amorphous nature of the ALD-deposited $\mathrm{TiO}_{2}$ [33], the electrode shows large irreversible discharging capacity at the first cycle with a broad plateau within $1.1 \mathrm{~V}-1.7 \mathrm{~V}$, which is different from crystalline $\mathrm{TiO}_{2}$, which has a typical voltage plateau at $1.7 \mathrm{~V}$ [56]. Large irreversible capacities in the first cycles are due to the formation of solid-electrolyte interface and incomplete Li-ion extraction [63-65]. We also notice that the capacity in the first cycle is larger than the theoretical capacity of $\mathrm{TiO}_{2}, 330 \mathrm{mAh} \cdot \mathrm{g}^{-1}$, likely due to the storage of $\mathrm{Li}$ ions in the grain boundary and interfaces of the nanostructured $\mathrm{TiO}_{2}[66]$.

A significant advantage of the $3 \mathrm{D} \mathrm{C} / \mathrm{TiO}_{2}$ electrodes is the long cycle life without the need of conducting additives and polymer binders. Figure 3a shows the prolonged electrochemical test of the $3 \mathrm{D} \mathrm{C} / \mathrm{TiO}_{2}$ electrodes with different $\mathrm{TiO}_{2}$ thicknesses at a test rate of $1 \mathrm{C}$. The $3 \mathrm{D} \mathrm{C} / \mathrm{TiO}_{2}$ electrode with $7 \mathrm{~nm}$ thick $\mathrm{ALD} \mathrm{TiO}_{2}$ shows very stable performance and lasts more than 1000 cycles with a capacity retention of $91 \%$ (Due to the large capacity loss in the first cycle, it is not reasonable to use the first-cycle capacity as the initial capacity. Here, the initial capacity is the third-cycle capacity, where the capacity stabilizes. The capacity retention is then calculated by dividing the initial capacity with the $1000^{\text {th }}$ cycle capacity). However, as the thickness of the $\mathrm{TiO}_{2}$ increases, the cycle life of the electrodes decreases. The capacity degrades to below $86 \%$ after 700 cycles for the $18 \mathrm{~nm} \mathrm{TiO}_{2}$ electrode and to below $87 \%$ after 400 cycles for the $27 \mathrm{~nm} \mathrm{TiO}$ electrode. Samples of $3 \mathrm{D} \mathrm{TiO}_{2}$ nano- 
network without any conducting network was also fabricated for comparison by depositing $\mathrm{TiO}_{2}$ on 3D PAA template using ALD process and then removing the 3D PAA template with $\mathrm{NaOH}$ solution. Without a 3D carbon nano-network, the $3 \mathrm{D} \mathrm{TiO}_{2}$ electrode with $7 \mathrm{~nm} \mathrm{TiO}_{2}$ layer delivers a small initial gravimetric capacity $\sim 100 \mathrm{mAh} \cdot \mathrm{g}^{-1}$ at $1 \mathrm{C}$ which degrades quickly to less than $50 \mathrm{mAh} \cdot \mathrm{g}^{-1}$ after 180 cycles. The fast degradation was also observed in earlier studies on nanostructured $\mathrm{TiO}_{2}$ electrodes, which are plotted in the same figure for comparison [57, 67]. This comparison clearly proves that the 3D carbon network helps prolong the cycle life of the $3 \mathrm{D} \mathrm{C} / \mathrm{TiO}_{2}$ electrodes.

An ex-situ TEM study of the electrodes was conducted to observe the change of the electrodes during the prolonged electrochemical test. The $3 \mathrm{D} \mathrm{C} / \mathrm{TiO}_{2}$ electrode with $7 \mathrm{~nm}$ $\mathrm{TiO}_{2}$ coating was carefully taken out of the coin cell after 150 cycles of electrochemical test and characterized with TEM. Figure $\mathbf{3 b}$ shows that the tubular structures are retained in the electrodes after 150 cycles, confirming the structural stability of the $3 \mathrm{D} \mathrm{C} / \mathrm{TiO}_{2}$ electrode. The $\mathrm{TiO}_{2}$ layer is still attached to both inside and outside of the carbon tubes. The total wall thickness increases to $33 \mathrm{~nm}$ with the $\mathrm{TiO}_{2}$ layer thickness increases to $12 \mathrm{~nm}$ after lithiation (the middle layer that consists of carbon and $\mathrm{ALD} \mathrm{Al}_{2} \mathrm{O}_{3}$ seed layer is increased to $9 \mathrm{~nm}$ in Section 7 of the Supporting information). Figure $3 \mathbf{c}$ shows the TEM images of the $3 \mathrm{D} C / \mathrm{TiO}_{2}$ electrode with $27 \mathrm{~nm} \mathrm{TiO}_{2}$ after 500 cycles. The tubular carbon structure still remained, but some of the tubes lost the $\mathrm{TiO}_{2}$ layer and the corresponding wall thickness reduced to $\sim 14 \mathrm{~nm}$. Although the volume change of $\mathrm{TiO}_{2}$ is only $3 \%$, the repeating insertion/extraction of $\mathrm{Li}$ ions can cause the detachment of $\mathrm{TiO}_{2}$ layer from the carbon network $[68,69]$. The $\mathrm{TiO}_{2}$ fallingoff from the carbon tubes leads to the capacity reduction.

Figure 4a shows the measured rate capabilities of $3 \mathrm{D} \mathrm{C} / \mathrm{TiO}_{2}$ electrodes with different $\mathrm{TiO}_{2}$ thicknesses on a $3 \mathrm{~nm}$ carbon nano-network. Here, $1 \mathrm{C}$ yields $235 \mathrm{~mA} \cdot \mathrm{g}^{-1}$ for $7 \mathrm{~nm}, 200$ $\mathrm{mA} \cdot \mathrm{g}^{-1}$ for $18 \mathrm{~nm}$ and $140 \mathrm{~mA} \cdot \mathrm{g}^{-1}$ for $27 \mathrm{~nm}$ thick $\mathrm{TiO}_{2}$. During the first 30 cycles, the test 
current was controlled to increase the charging/discharging rate after every 5 cycles. When the test rates are slow $(\leq \mathrm{C} / 2.5)$, the $3 \mathrm{D} \mathrm{C} / \mathrm{TiO}_{2}$ electrodes with $7 \mathrm{~nm}$ and $18 \mathrm{~nm} \mathrm{TiO}_{2}$ show very similar capacities, while the $28 \mathrm{~nm} \mathrm{TiO} 2$ electrode shows lower capacities. At low test rates, the thickness of the $\mathrm{TiO}_{2}$ layers is so thin that the $\mathrm{Li}$ ions are able to diffuse through the active materials without impacting the rate capability. However, a decrease of capacity is observed in thick $\mathrm{TiO}_{2}$ electrode when the time needed for $\mathrm{Li}$ ion to diffuse through the solid $\mathrm{TiO}_{2}$ is comparable to the charging/discharging time constant. At higher rates, all three of the samples show considerable capacity loss. The thicker the $\mathrm{TiO}_{2}$ layers, the larger the capacity loss. For example, the $7 \mathrm{~nm} \mathrm{TiO}_{2}$ sample only delivers a gravimetric capacity of $\sim 117.5$ $\mathrm{mAh} \cdot \mathrm{g}^{-1}$ at a test rate of $10 \mathrm{C}$, which is only $38 \%$ of its capacity at $\mathrm{C} / 10$.

There are three different mechanisms that cause the capacity degradation at high rates: 1) Longer diffusion length and diffusion time of the $\mathrm{Li}$ ions in the thicker $\mathrm{TiO}_{2}$ layer reduce the rate capability. 2) Current collection ability of the 3D carbon network might be too low to match with the generation due to fast $\mathrm{Li}$ ion reaction. 3) Starting with the same pore size in the PAA templates, a thicker $\mathrm{TiO}_{2}$ layer reduces the pore size in the electrode that greatly affects the permeability of $\mathrm{Li}$ ions, which consumes more $\mathrm{Li}$ ions and ultimately causes faster Li ion depletion.

In Figure 4b, the rate capabilities of $\mathrm{TiO}_{2}$ nanostructures with and without conducting networks are compared to illlustrate the effect of electrical conductivity $[47,67$, 70]. Both the nanostructured $\mathrm{TiO}_{2}$ electrodes without any conducting network and the nanostructured $\mathrm{TiO}_{2}$ electrodes made by mixing carbon black or graphene in conventional ways show lower capacities than our $3 \mathrm{D} \mathrm{C} / \mathrm{TiO}_{2}$ network. the electrical conductivity of the $3 \mathrm{D}$ carbon network with $3 \mathrm{~nm}$ carbon layer is $\sim 110 \mathrm{~S} \cdot \mathrm{m}^{-1}$. When the carbon layer thickness is increased from $3 \mathrm{~nm}$ to $8 \mathrm{~nm}$, the electrical conductivity increases to $159 \mathrm{~S} \cdot \mathrm{m}^{-1}$. The improvement of rate capability of $3 \mathrm{D} \mathrm{C} / \mathrm{TiO}_{2}$ nano-network elecrodes due to the increase of 
the electrical conductivity of electrodes is clearly shown by comparing the LIB electrode performance of $3 \mathrm{~nm}$ and $8 \mathrm{~nm}$ thick carbon. A further enhancement on rate capability due to electrical conductivity of electrodes is evidenced by comparing the rate capability of 3D $\mathrm{C} / / \mathrm{TiO}_{2}$ and $\mathrm{Ni} / \mathrm{TiO}_{2}$ network electrodes. Our earlier work showed that $3 \mathrm{D} \mathrm{Ni} / \mathrm{TiO}_{2}$ nanowire network has an electrical conductivity of $\sim 10^{6} \mathrm{~S} \cdot \mathrm{m}^{-1}$ [33]. However, considering that the metal conducting network would reduce the gravimetric capacity of the electrodes due to the high weight percentage of inactive metallic materials, it is desirable to increase the electrical conductivity of the 3D carbon nano-network.

At high rates, large capacity loss is observed even with the highly conductive $3 \mathrm{D} \mathrm{Ni}$ network, which is likely due to the low permeation rate and depletion of $\mathrm{Li}$ ions in such 3D electrodes. Figure $4 \mathbf{c}$ compares normalized rate capability of $\mathrm{TiO}_{2}$ film electrodes, the 3D $\mathrm{Ni} / \mathrm{TiO}_{2}$ nanowire network electrode, and the $3 \mathrm{D} \mathrm{C} / \mathrm{TiO}_{2}$ nano-network electrode with similar $\mathrm{TiO}_{2}$ thicknesses. Their capacities at different test rates are normalized to their capacity at $\mathrm{C} / 10$. Here the $\mathrm{TiO}_{2}$ film electrode is fabricated by directly depositing $\mathrm{TiO}_{2}$ layer on $\mathrm{Cu}$ foil current collector using ALD process. In thin film electrodes, the electrons are directly transported to the current collector when generated and the electrolyte has direct access to $\mathrm{TiO}_{2}$ active material without any permeation resistance or depletion problem. At low rates $(<1 \mathrm{C})$, the $3 \mathrm{D} \mathrm{Ni} / \mathrm{TiO}_{2}$ and the $\mathrm{TiO}_{2}$ film electrodes exhibit similar capacity loss, which indicates that the permeation of Li ions in the 3D architecture is sufficient and does not harm the rate capability. However, a much larger capacity loss is observed in $3 \mathrm{D} \mathrm{C} / \mathrm{TiO}_{2}$ electrode with a lower electrical conductivity, which indicates that electron transport plays an important role in the rate capability of these electrodes at low rates. When the test rate is much higher than $1 \mathrm{C}$, the capacities of both $3 \mathrm{D} \mathrm{Ni} / \mathrm{TiO}_{2}$ and $3 \mathrm{D} \mathrm{C} / \mathrm{TiO}_{2}$ drop dramatically, while that of the $\mathrm{TiO}_{2}$ film only drops slightly, which indicates that the permeation resistance and depletion of 
Li ions could play an important role in the capacity loss at high test rates in such 3D electrodes.

\section{Conclusions}

In summary, we have successfully fabricated a 3D carbon nano-network by CVD of carbon on scalably manufactured 3D porous anodized alumina templates. The manufacturing of the 3D carbon nano-network is also scalable in terms of sample size, the thickness of carbon layer, and the diameters of carbon nanotubes. The highly conductive 3D carbon nanonetwork can be used to significantly enhance the performance of LIB electrodes made of low conductivity active materials. As a proof-of-concept demonstration, $3 \mathrm{D} \mathrm{C} / \mathrm{TiO}_{2}$ nano-network electrodes are fabricated by uniformly coating $\mathrm{TiO}_{2}$ on the $3 \mathrm{D}$ carbon nano-network using the atomic layer deposition process. A large areal capacity of $\sim 0.37 \mathrm{mAh} \cdot \mathrm{cm}^{-2}$ is achieved in 60 $\mu \mathrm{m}$ thick $3 \mathrm{D} \mathrm{C} / \mathrm{TiO}_{2}$ electrode due to the large mass loading of active material $\mathrm{TiO}_{2}$. At a test rate of $\mathrm{C} / 5$, the electrode with $18 \mathrm{~nm}$-thick $\mathrm{TiO}_{2}$ uniformly coated on the $3 \mathrm{D}$ carbon nanonetwork delivers a high gravimetric capacity of $\sim 240 \mathrm{mAh} \cdot \mathrm{g}^{-1}$ using the mass of the whole electrode in the calculation. High areal capacity and large grevimetric capacity based on the whole electrode render high energy density of the whole battery.A long cycle life of over 1000 cycles is demonstrated at $1 \mathrm{C}$ with a capacity retention of $91 \%$. The effects of the electrical conductivity of carbon nano-network, ion diffusion in the active material, and the electrolyte permeability, on the rate performance of these $3 \mathrm{D} \mathrm{C} / \mathrm{TiO}_{2}$ electrodes are systematically studied, which gives insights on high performance LIB electrodes with 3D architecture.

\section{Acknowledgements}

This work was supported by the DARPA Center on Nanoscale Science and Technology for Integrated Micro/Nano-Electromechanical Transducers (iMINT), supported by the Defense Advanced Research Projects Agency (DARPA) N/MEMS S\&T Fundamentals program under 
grant no. N66001-10-1-4007 issued by the Space and Naval Warfare Systems Center Pacific (SPAWAR). Some of the micro/nano-fabrication work was conducted in the Colorado Nanofabrication Laboratories, supported in part by the NNIN and the National Science Foundation under Grant No. ECS-0335765. The TEM charaterization work work was performed at the Center for Integrated Nanotechnologies, an Office of Science User Facility operated for the U.S. Department of Energy (DOE) Office of Science. Sandia National Laboratories is a multi-program laboratory managed and operated by Sandia Corporation, a wholly owned subsidiary of Lockheed Martin Corporation, for the U.S. Department of Energy's National Nuclear Security Administration under contract DE-AC04-94AL85000.

\section{References:}

[1] C. Liu, F. Li, L.-P. Ma, H.-M. Cheng, Adv. Mater., 22 (2010) E28-E62.

[2] R.F. Nelson, J. Power Sources, 91 (2000) 2-26.

[3] E. Karden, S. Ploumen, B. Fricke, T. Miller, K. Snyder, J. Power Sources, 168 (2007) 211.

[4] H. Kim, B. Han, J. Choo, J. Cho, Angew. Chem. Int. Ed., 47 (2008) 10151-10154.

[5] B. Liu, P. Soares, C. Checkles, Y. Zhao, G. Yu, Nano Lett., 13 (2013) 3414-3419.

[6] Y. Zhao, B. Liu, L. Pan, G. Yu, Energy Environ. Sci., 6 (2013) 2856-2870.

[7] H. Zhang, X. Yu, P. Braun, Nat Nanotechnol, 6 (2011) 277-281.

[8] M.M. Shaijumon, E. Perre, B. Daffos, P.-L. Taberna, J.-M. Tarascon, P. Simon, Adv Mater, 22 (2010) 4978-4981.

[9] P.L. Taberna, S. Mitra, P. Poizot, P. Simon, J.M. Tarascon, Nat. Mater., 5 (2006) 567-573.

[10] S.K. Cheah, E. Perre, M. Rooth, M. Fondell, A. Hårsta, L. Nyholm, M. Boman, T.r. Gustafsson, J. Lu, P. Simon, K. Edström, Nano Lett., 9 (2009) 3230-3233.

[11] H. Zhang, P.V. Braun, Nano Lett., 12 (2012) 2778-2783.

[12] M. Mecklenburg, A. Schuchardt, Y.K. Mishra, S. Kaps, R. Adelung, A. Lotnyk, L. Kienle, K. Schulte, Adv Mater, 24 (2012) 3486-3490.

[13] J. Moskon, R. Dominko, M. Gaberscek, R. Cerc-Korosec, J. Jamnik, J. Electrochem. Soc., 153 (2006) A1805-A1811.

[14] Z.-S. Wu, S. Yang, Y. Sun, K. Parvez, X. Feng, K. Müllen, J. Am. Chem. Soc., 134 (2012) 9082-9085.

[15] M. Rose, E. Kockrick, I. Senkovska, S. Kaskel, Carbon, 48 (2010) 403-407.

[16] L.L. Zhang, X. Zhao, M.D. Stoller, Y. Zhu, H. Ji, S. Murali, Y. Wu, S. Perales, B. Clevenger, R.S. Ruoff, Nano Lett., 12 (2012) 1806-1812.

[17] A.L.M. Reddy, M.M. Shaijumon, S.R. Gowda, P.M. Ajayan, Nano Lett., 9 (2009) $1002-$ 1006.

[18] I. Lahiri, S.-W. Oh, J.Y. Hwang, S. Cho, Y.-K. Sun, R. Banerjee, W. Choi, ACS Nano, 4 (2010) 3440-3446.

[19] E.G. Calvo, C.O. Ania, L. Zubizarreta, J.A. Menéndez, A. Arenillas, Energy \& Fuels, 24 (2010) 3334-3339. 
[20] D.R. Rolison, J.W. Long, J.C. Lytle, A.E. Fischer, C.P. Rhodes, T.M. McEvoy, M.E. Bourg, A.M. Lubers, Chem. Soc. Rev., 38 (2009) 226.

[21] J.C. Lytle, J.M. Wallace, M.B. Sassin, A.J. Barrow, J.W. Long, J.L. Dysart, C.H. Renninger, M.P. Saunders, N.L. Brandell, D.R. Rolison, Energy Environ. Sci., 4 (2011) 1913-1925.

[22] Y. Zhu, H. Hu, W.-C. Li, X. Zhang, J. Power Sources, 162 (2006) 738-742.

[23] N. Liu, J. Shen, D. Liu, Electrochim. Acta, 97 (2013) 271-277.

[24] Y. Piao, H.S. Kim, Y.-E. Sung, T. Hyeon, Chem Commun, 46 (2010) 118-120.

[25] X. Yang, K. Fan, Y. Zhu, J. Shen, X. Jiang, P. Zhao, C. Li, J. Mater. Chem., 22 (2012) 17278-17283.

[26] L. Dimesso, C. Spanheimer, S. Jacke, W. Jaegermann, J. Power Sources, 196 (2011) 6729-6734.

[27] P. Johns, M. Roberts, J. Owen, J. Mater. Chem., 21 (2011) 10153-10159.

[28] C.M. Doherty, R.A. Caruso, B.M. Smarsly, P. Adelhelm, C.J. Drummond, Chem. Mater., 21 (2009) 5300-5306.

[29] H. Ji, L. Zhang, M.T. Pettes, H. Li, S. Chen, L. Shi, R. Piner, R.S. Ruoff, Nano Lett., 12 (2012) 2446-2451.

[30] B. Ding, C. Yuan, L. Shen, G. Xu, P. Nie, X. Zhang, Chem. Eur. J., 19 (2013) 1013-1019.

[31] X. Huang, J. Chen, Z. Lu, H. Yu, Q. Yan, H.H. Hng, Sci. Rep., 3 (2013).

[32] M. Tian, W. Wang, Y. Wei, R. Yang, J. Power Sources, 211 (2012) 46-51.

[33] W. Wang, M. Tian, A. Abdulagatov, S.M. George, Y.-C. Lee, R. Yang, Nano Lett., 12 (2012) 655-660.

[34] J.C. Yoon, J.S. Lee, S.I. Kim, K.H. Kim, J.H. Jang, Sci. Rep., 3 (2013).

[35] Y.C. Sui, J.A. González-León, A. Bermúdez, J.M. Saniger, Carbon, 39 (2001) 1709-1715.

[36] S.M. George, Chem. Rev., 110 (2010) 111-131.

[37] S.Y. Chung, J.T. Bloking, Y.M. Chiang, Nat. Mater., 1 (2002) 123-128.

[38] M. Schmidt, U. Heider, A. Kuehner, R. Oesten, M. Jungnitz, N. Ignat'ev, P. Sartori, J. Power Sources, 97-98 (2001) 557-560.

[39] J.T. Dudley, D.P. Wilkinson, G. Thomas, R. LeVae, S. Woo, H. Blom, C. Horvath, M.W. Juzkow, B. Denis, P. Juric, P. Aghakian, J.R. Dahn, J. Power Sources, 35 (1991) 5982.

[40] D.W. Dees, K.G. Gallagher, D.P. Abraham, A.N. Jansen, J. Electrochem. Soc., 160 (2013) A478-A486.

[41] F. Fabregat-Santiago, I. Mora-Seró, G. Garcia-Belmonte, J. Bisquert, J. Phys. Chem. B, 107 (2002) 758-768.

[42] H. Liang, F. Chen, R. Li, L. Wang, Z. Deng, Electrochim. Acta, 49 (2004) 3463-3467.

[43] H. Ming, J. Ming, X. Li, Q. Zhou, H. Wang, L. Jin, Y. Fu, J. Adkins, J. Zheng, Electrochim. Acta, 116 (2014) 224-229.

[44] X. Chen, S.S. Mao, Chem. Rev., 107 (2007) 2891-2959.

[45] Z. Yang, G. Du, Z. Guo, X. Yu, Z. Chen, T. Guo, H. Liu, J. Mater. Chem., 21 (2011) 8591-8596.

[46] I. Moriguchi, Y. Shono, H. Yamada, T. Kudo, J. Phys. Chem. B, 112 (2008) 1456014565.

[47] L. He, R. Ma, N. Du, J. Ren, T. Wong, Y. Li, S.T. Lee, J. Mater. Chem., 22 (2012) 19061-19066.

[48] S.J. Park, Y.J. Kim, H. Lee, J. Power Sources, 196 (2011) 5133-5137.

[49] Y.S. Jung, A.S. Cavanagh, L.A. Riley, S.H. Kang, A.C. Dillon, M.D. Groner, S.M. George, S.H. Lee, Adv Mater, 22 (2010) 2172-+.

[50] L.A. Riley, S. Van Ana, A.S. Cavanagh, Y.F. Yan, S.M. George, P. Liu, A.C. Dillon, S.H. Lee, J. Power Sources, 196 (2011) 3317-3324. 
[51] A.I. Abdulagatov, Y. Yan, J.R. Cooper, Y. Zhang, Z.M. Gibbs, A.S. Cavanagh, R.G. Yang, Y.C. Lee, S.M. George, ACS Appl. Mater. Interfaces, 3 (2011) 4593-4601.

[52] Y. Huang, G. Pandraud, P.M. Sarro, J. Vac. Sci. Technol., A: Vacuum, Surfaces, and Films, 31 (2013) 01A148-148.

[53] W. Wei, G. Oltean, C.-W. Tai, K. Edstrom, F. Bjorefors, L. Nyholm, J. Mater. Chem. A, 1 (2013) 8160-8169.

[54] W.-H. Ryu, D.-H. Nam, Y.-S. Ko, R.-H. Kim, H.-S. Kwon, Electrochim. Acta, 61 (2012) 19-24.

[55] D. Liu, Y. Zhang, P. Xiao, B.B. Garcia, Q. Zhang, X. Zhou, Y.-H. Jeong, G. Cao, Electrochim. Acta, 54 (2009) 6816-6820.

[56] T. Yiping, T. Xiaoxu, H. Guangya, C. Huazhen, Z. Guoqu, Electrochim. Acta, 78 (2012) 154-159.

[57] S. Hyun-Woo, L. Duk Kyu, C. In-Sun, H. Kug Sun, K. Dong-Wan, Nanotechnology, 21 (2010) 255706.

[58] M. Anji Reddy, V. Pralong, U.V. Varadaraju, B. Raveau, Electrochem. Solid-State Lett., 11 (2008) A132-A134.

[59] K. Wang, M. Wei, M.A. Morris, H. Zhou, J.D. Holmes, Adv. Mater., 19 (2007) 30163020.

[60] H. Xiong, H. Yildirim, E.V. Shevchenko, V.B. Prakapenka, B. Koo, M.D. Slater, M. Balasubramanian, S.K.R.S. Sankaranarayanan, J.P. Greeley, S. Tepavcevic, N.M. Dimitrijevic, P. Podsiadlo, C.S. Johnson, T. Rajh, J. Phys. Chem. C, 116 (2011) 3181 3187.

[61] W.J.H. Borghols, D. Lützenkirchen-Hecht, U. Haake, W. Chan, U. Lafont, E.M. Kelder, E.R.H. van Eck, A.P.M. Kentgens, F.M. Mulder, M. Wagemaker, J. Electrochem. Soc., 157 (2010) A582-A588.

[62] B. Chunmei, X. Ming, S. Xiang, J.T. Jonathan, W. Gongkai, S. Hongtao, C.D. Anne, L. Jie, M.G. Steven, Nanotechnology, 24 (2013) 424002.

[63] J. Xu, C. Jia, B. Cao, W.F. Zhang, Electrochim. Acta, 52 (2007) 8044-8047.

[64] X.D. Sun, C.L. Ma, Y.D. Wang, H.D. Li, Nanotechnology, 15 (2004) 1535.

[65] G.F. Ortiz, I. Hanzu, T. Djenizian, P. Lavela, J.L. Tirado, P. Knauth, Chem. Mater., 21 (2008) 63-67.

[66] M.M. Rahman, J.-Z. Wang, M.F. Hassan, D. Wexler, H.K. Liu, Adv. Energy Mater., 1 (2011) 212-220.

[67] P. Kubiak, T. Froschl, N. Husing, U. Hormann, U. Kaiser, R. Schiller, C.K. Weiss, K. Landfester, M. Wohlfahrt-Mehrens, Small, 7 (2011) 1690-1696.

[68] M. Wagemaker, G.J. Kearley, A.A. van Well, H. Mutka, F.M. Mulder, J. Am. Chem. Soc., 125 (2002) 840-848.

[69] D. Wang, D. Choi, Z. Yang, V.V. Viswanathan, Z. Nie, C. Wang, Y. Song, J.-G. Zhang, J. Liu, Chem. Mater., 20 (2008) 3435-3442.

[70] D.H. Wang, D.W. Choi, J. Li, Z.G. Yang, Z.M. Nie, R. Kou, D.H. Hu, C.M. Wang, L.V. Saraf, J.G. Zhang, I.A. Aksay, J. Liu, ACS Nano, 3 (2009) 907-914. 


\section{Figure Captions}

Figure 1. a) Optical image of a free-standing 3D carbon nano-network. b) cross-sectional SEM image and c) TEM image of the 3D carbon nano-network after 3.5 hours of carbon CVD. d) \& e) HR-TEM image of the 3D carbon nano-network from the marked area in c) and d), respectively. Inset in e): electron diffraction pattern of the 3D carbon nano-network. f) HRTEM image of the 3D carbon nano-network with ALD $\mathrm{TiO}_{2}$ coating. Inset: electron diffraction pattern of the $3 \mathrm{D} \mathrm{C} / \mathrm{TiO}_{2}$ nano-network.

Figure 2. a) Areal capacities of the $3 \mathrm{D} \mathrm{C} / \mathrm{TiO}_{2}$ electrodes with different thicknesses of $\mathrm{TiO}_{2}$ on $3 \mathrm{~nm}$-thick carbon nano-network. b) Gravimetric capacities of the $3 \mathrm{D} \mathrm{C} / \mathrm{TiO}_{2}$ electrodes with different thicknesses of $\mathrm{TiO}_{2}$ on $3 \mathrm{~nm}$-thick carbon nano-network. The open symbol plots are calculated using only the weight of $\mathrm{TiO}_{2}$ and the solid symbol plots are calculated using whole electrode weight. c) Galvanostatic discharging/charging curves of the $3 \mathrm{D} \mathrm{C} / \mathrm{TiO}_{2}$ electrode with $7 \mathrm{~nm} \mathrm{TiO}_{2}$ coating on $3 \mathrm{~nm}$-thick 3D carbon nano-network. Test rate is $\mathrm{C} / 10$ for the first two cycles and then $\mathrm{C} / 5$ for the rest of the curves.

Figure 3. a) Stability of the $3 \mathrm{D} \mathrm{C} / \mathrm{TiO}_{2}$ electrodes with different thicknesses of $\mathrm{ALD} \mathrm{TiO}_{2}$ on $3 \mathrm{~nm}$-thick carbon nano-network at a test rate of $1 \mathrm{C}$, in comparison with $\mathrm{TiO}_{2}$ nanowires[57], $\mathrm{TiO}_{2}$ nanoparticles[67], and $3 \mathrm{D} \mathrm{TiO}_{2}$ without carbon nano-network. b) TEM image of the $\mathrm{C} / \mathrm{TiO}_{2}$ structure with $7.5 \mathrm{~nm}$-thick $\mathrm{TiO}_{2}$ on 3 nm-thick carbon nano-network after 150 charging/discharging cycles. c) $\mathrm{TEM}$ image of the $\mathrm{C} / \mathrm{TiO}_{2}$ structure with $27 \mathrm{~nm}$-thick $\mathrm{TiO}_{2}$ on 3 nm-thick carbon nano-network after 500 charging/discharging cycles.

Figure 4. a) Rate capability of $3 \mathrm{D} \mathrm{C} / \mathrm{TiO}_{2}$ electrodes with different thicknesses of $\mathrm{ALD} \mathrm{TiO}_{2}$ coatings on 3 nm-thick carbon nano-network. b) Rate capabilities of $\mathrm{TiO}_{2}$ electrodes with different conducting networks. c) Normalized rate capabilities of $\mathrm{TiO}_{2}$ electrodes with different conducting networks. 


\section{Figure 1}

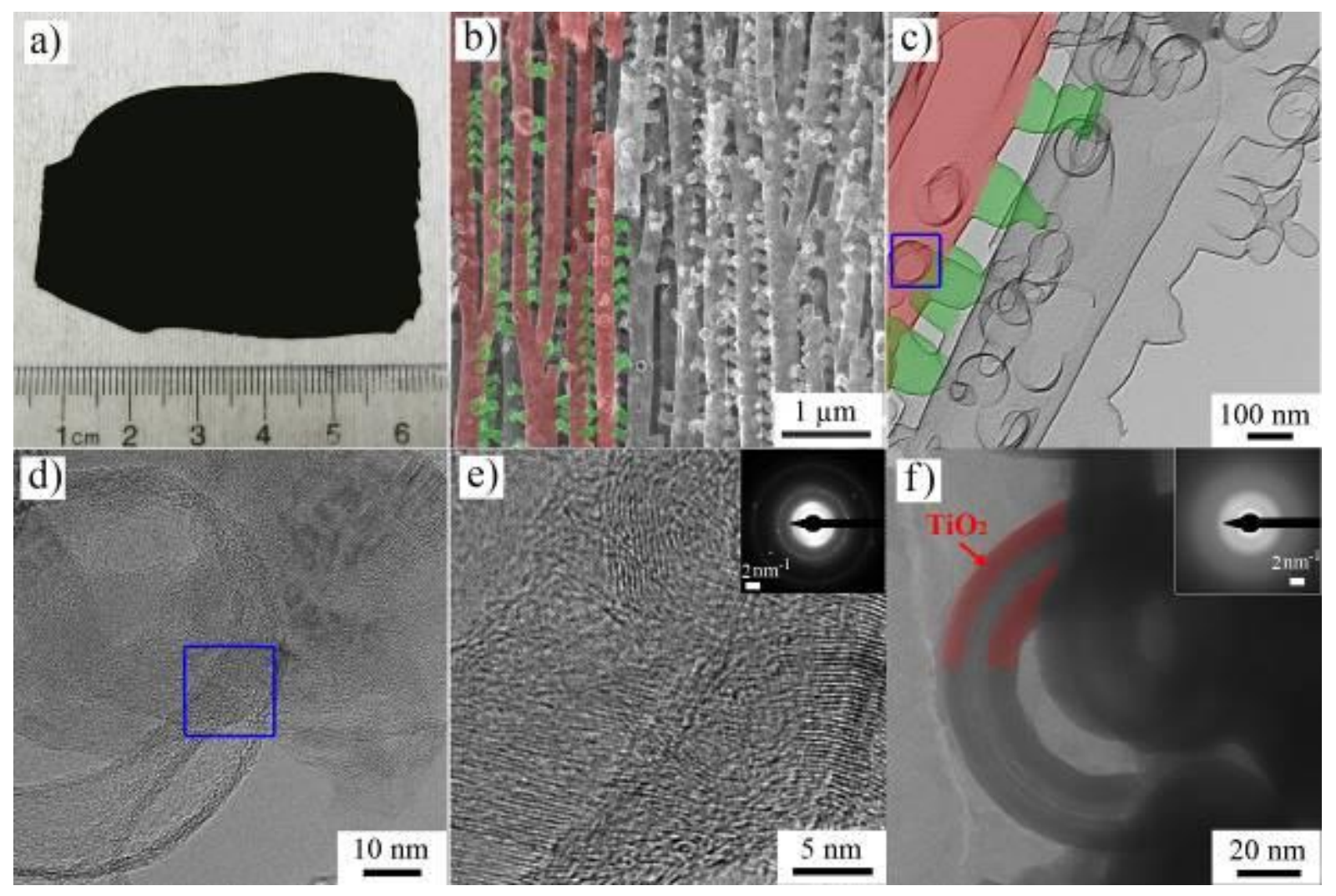

Figure 2
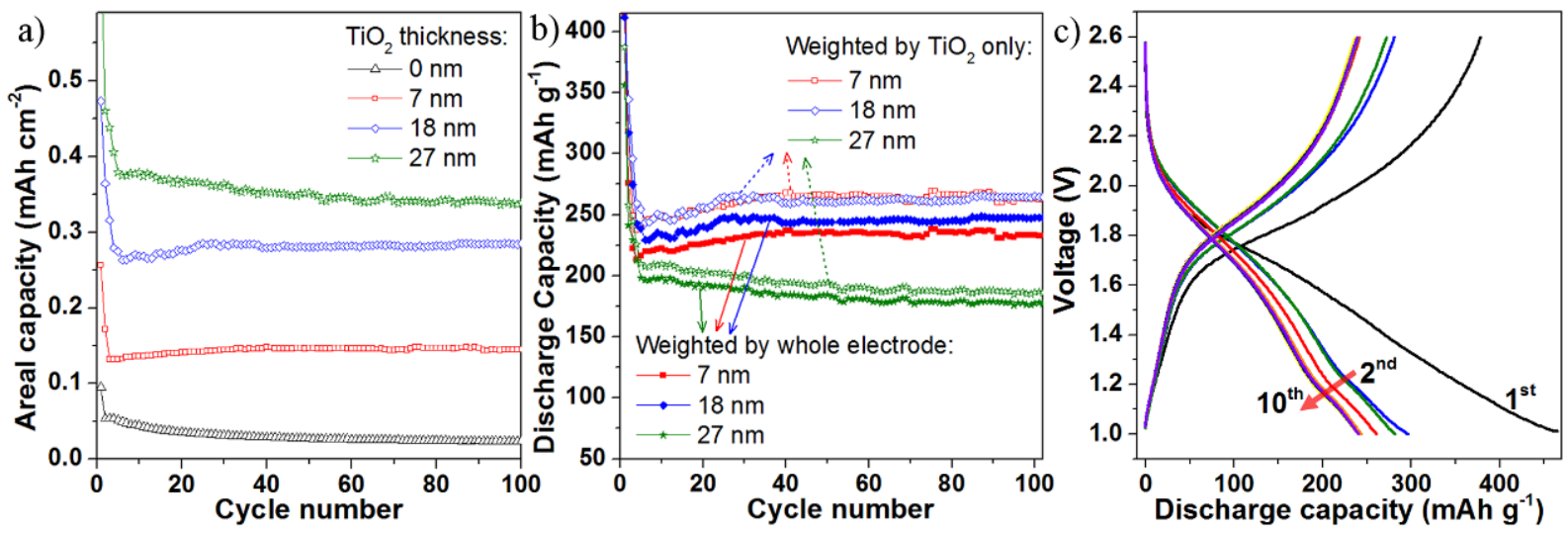
Figure 3
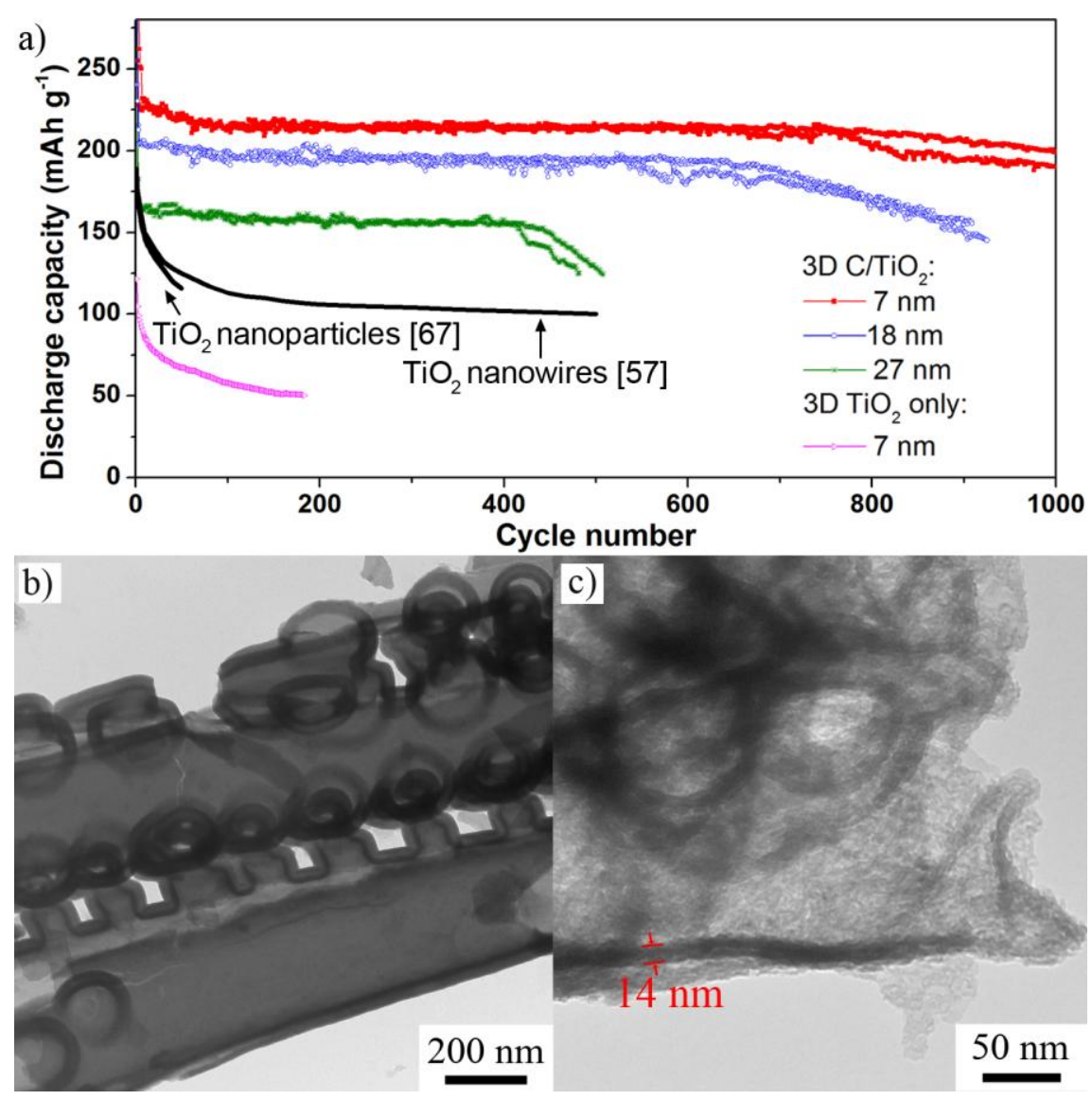

Figure 4
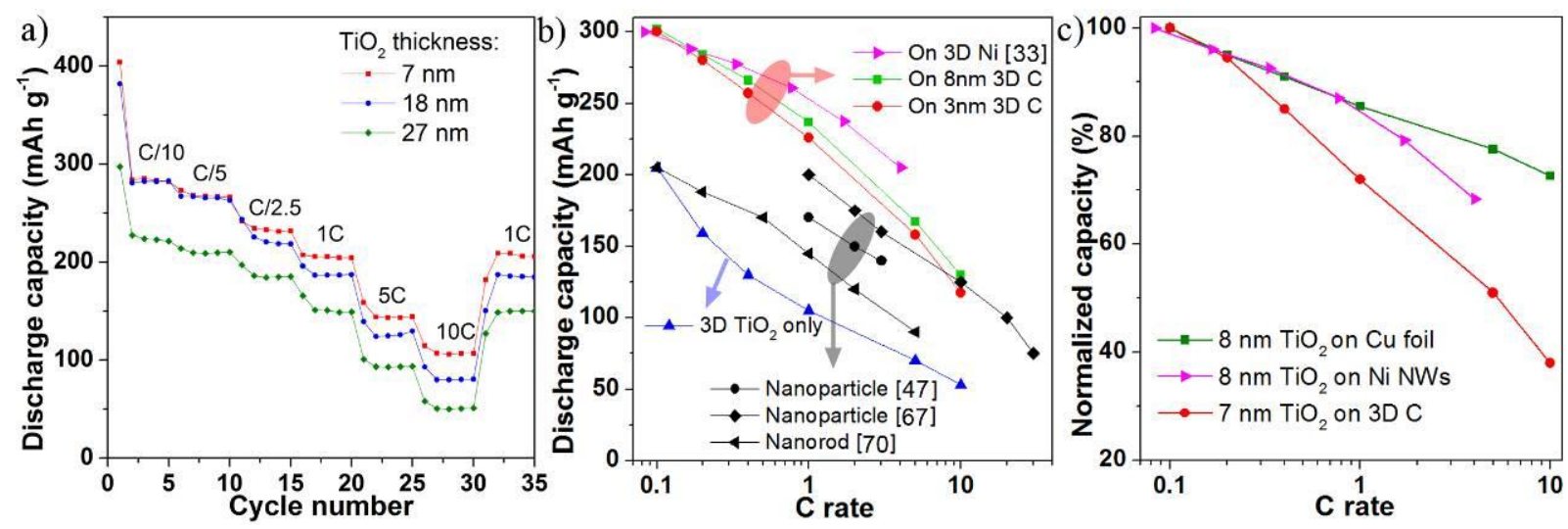